\title{
Defining fundamental niche dimensions of corals: synergistic effects of colony size, light, and flow
}

\author{
Mia O. Hoogenboom ${ }^{1}$ and Sean R. Connolly \\ ARC Centre of Excellence for Coral Reef Studies and School of Marine and Tropical Biology, James Cook University, \\ Townsville, Queensland 4811 Australia
}

\begin{abstract}
The "fundamental niche" is the range of conditions under which an organism can survive and reproduce, measured in the absence of biotic interactions. Niche measurements are often based on statistical relationships between species presence and measured environmental variables, or inferred from measured responses of species along hypothesized niche axes. In this study, we use novel, process-based models of how irradiance and gas diffusion influence photosynthesis and respiration to predict niche dimensions for three coral species: Acropora nasuta, Montipora foliosa, and Leptoria phrygia. We use a combination of mathematical modeling, laboratory experiments, and field observations to establish the link between energy acquisition and the dominant environmental gradients on reefs: light intensity and water flow velocity. Our approach allows us to quantify how the shape of the niche varies in response to light and flow conditions. The model predicts that, due to its higher photosynthetic capacity, the branching coral $A$. nasuta has a positive energy balance over a wider range of conditions than both a massive species (L. phrygia) and a foliose species (M. foliosa). Moreover, colony size influences niche width, with larger colonies of all three species achieving a positive energy balance over a broader range of conditions than small colonies. Comparison of model predictions with field data demonstrated that tissue biomass and reproductive output are significantly and positively correlated with predicted energy acquisition. These results show how interactions between light and flow determine organism performance along environmental gradients on coral reefs. In addition, this study demonstrates the utility of process-based models for quantifying how physiology influences ecology, and for predicting the ecological consequences of varying environmental conditions.

Key words: Acropora nasuta; carbon acquisition; fundamental niche; Leptoria phrygia; light intensity; mass transfer coefficient; Montipora foliosa; photosynthesis; physiological model; scleractinian corals; water flow velocity.
\end{abstract}

\section{INTRODUCTION}

The niche is an important concept in ecology that allows consideration of the roles of biotic and abiotic processes in shaping species distributions (e.g., Connell 1961). Although this term carries many different meanings (e.g., Whittaker et al. 1973, Chase and Leibold 2003), the "fundamental niche" was initially defined as the range of conditions under which an organism can survive and reproduce in the absence of biotic interactions (e.g., Hutchinson 1957). Over time, methods for measuring the niche have evolved from a conceptual "hypervolume" (Hutchinson 1957), to statistical techniques that identify environmental variables that are strong correlates of species occurrence (e.g., Austin et al. 1990, Wright et al. 2006). Another approach is to experimentally quantify organism performance (e.g., growth) along hypothesized niche axes (e.g., Greulich

Manuscript received 7 December 2007; revised 27 May 2008; accepted 16 June 2008. Corresponding Editor: R. B. Aronson.

${ }^{1}$ Present address: Centre Scientifique de Monaco, Avenue St. Martin, MC98000 Monaco.

E-mail:mia@centrescientifique.mc et al. 2000, Antoine and McCune 2004). Although these techniques identify correlates of species occurrence, they do not characterize the processes that underlie such relationships. An alternative is to describe the niche based on the underlying mechanisms that determine how specific environmental conditions influence organism performance. Although there are few examples of this approach, in one such effort, Kearney and Porter (2004) combined physiological measurements, biophysical models, and climate data to describe the fundamental niche of a lizard. Mechanistic approaches to niche studies are beneficial because they explicitly identify drivers of species' distributions, and allow greater confidence when extrapolating niche properties to conditions not included in multivariate data sets (Pulliam 2000, Kearney 2006).

An additional complication for niche measurement is that over the course of an organism's life, changes in body size can alter how the environment influences individuals. These ontogenetic changes are most commonly observed in "trophic niches": for example, as predators grow larger, their prey selection changes (e.g., Scharf et al. 2000). However, such effects are also likely 
to be evident in the niche of sessile organisms, particularly because they are committed to their site of settlement irrespective of any unfavorable conditions that may prevail as they grow larger. Although investigations of this kind are rare, rain forest plants occur under a broader range of conditions as juveniles than as adults (Webb and Peart 2000). Similarly, correlative approaches to niche measurement indicate that, for some taxa, the presence of juveniles may be predicted by a different set of environmental variables than that identified for adults (e.g., tree ferns [Jones et al. 2007]).

Physiology and energy balance are fundamental to organism performance (Kooijman 2000, Kearney 2006). Therefore, the axes delimiting the fundamental niche should include those variables that influence energy and mass balance (Kearney and Porter 2004). For photosynthetic organisms, generating energy for growth and reproduction requires light to activate the photosynthetic machinery, together with exchange of $\mathrm{CO}_{2}$ and $\mathrm{O}_{2}$ gases during carbon fixation and metabolism (e.g., Falkowski and Raven 1997). Despite the existence of general principles that describe diffusion of gases from smooth surfaces, such models do not include light intensity as a factor influencing photosynthesis under natural conditions (e.g., Patterson et al. 1991). Therefore, although it is clear that the niche is strongly influenced by both light intensity and gas exchange, the interactive effects of these processes on the size and location of the fundamental niche are unknown. The primary aim of this study was to develop a model of energy acquisition as a function of light, gas exchange, and organism size, and to use this framework to describe the fundamental niche of three coral species.

Reef-building corals inhabit heterogeneous environments in which light intensity and water flow (i.e., potential gas exchange) decrease with depth (Helmuth et al. 1997a). Therefore, corals are appropriate model organisms for developing mechanistic hypotheses about the relationships between environmental gradients and the fundamental niche. In this study, we use a combination of mathematical modeling, laboratory experiments, and field observations to model the niche. Under Hutchinson's definition of the fundamental niche, identifying the conditions under which species are able to survive and reproduce requires knowledge of environmental effects on birth and death rates. In some cases, such rates cannot be readily quantified. For example, for organisms with highly dispersive offspring, such as corals, the fraction of offspring produced by an individual that survive to establish as juveniles cannot be reliably determined. In these cases, physiological or energetic proxies of the capacity for population growth are often used (e.g., Anthony and Connolly 2004, Kearney and Porter 2004). We here define the niche as the conditions under which individuals have a positive energy balance. In other words, we delineate the conditions under which individuals are able to survive, and have a surplus of energy that may be allocated to reproduction. This definition of the niche is based on a central concept of ecophysiology and life-history theory: that all organisms require a net gain in energy for growth, reproduction, and survival to be possible (Kooijman 2000). Specifically, we aimed to: (1) measure niche width along gradients of light and flow for different coral species; and (2) explicitly account for colony size as a potential factor influencing niche size. To assess the predictive accuracy of this model we compared predicted energy acquisition with measures of tissue quality and reproduction for colonies of known size, sampled from field sites where light and flow were also quantified.

\section{Methods \\ Modeling framework}

Corals are symbiotic organisms that obtain the majority of their energy (carbon) from photosynthesis (e.g., Muscatine et al. 1981). In all environments, photosynthetic gas exchange occurs across a diffusive boundary layer (DBL, i.e., a layer of stagnant fluid adjacent to the photosynthesizing surface [Nobel 1983]). The rate at which molecules diffuse across DBLs depends upon the concentration of molecules on either side of the layer, and the overall thickness of the layer (Fick's laws [Nobel 1983]). In turn, DBL thickness depends upon fluid velocity and turbulence (Nobel 1983, Denny 1988). Based on this principle, general models of gas exchange have been developed. These models relate photosynthesis to water flow using nondimensional parameters (Reynolds number, Re, and Sherwood number, Sh) to quantify the extent to which mass flux is enhanced by fluid motion relative to that possible through diffusion (e.g., Helmuth et al. 1997a, Falter et al. 2007). Re summarizes the ratio of inertial to viscous forces of the fluid, and characterizes flow over a surface (Denny 1988):

$$
\operatorname{Re}=\frac{u W}{v}
$$

where $u$ is flow velocity, $W$ is organism size (e.g., length in the direction of flow) and $v$ is the kinematic viscosity of the fluid. Sh indicates how much mass flux is assisted by direct transfer (advection) relative to the potential flux if diffusion was the only mechanism operating (Denny 1988, Patterson 1992), and is given by

$$
\mathrm{Sh}=\frac{h_{\mathrm{m}} W}{D}
$$

where $h_{\mathrm{m}}$ is the mass transfer coefficient, and $D$ is the diffusion coefficient (i.e., the time taken for the gas to diffuse a set distance [Denny 1988]). The relationship between $\mathrm{Sh}$ and $\mathrm{Re}$ has been well characterized experimentally, as

$$
\mathrm{Sh}=a \operatorname{Re}^{b}
$$


TABLE 1. Definitions of mass transport parameters.

\begin{tabular}{|c|c|c|}
\hline Parameter & Definition (units) & Estimate and source \\
\hline$v$ & Kinematic viscosity of seawater $\left(\mathrm{cm}^{2} / \mathrm{s}\right)$ & $10^{-2}$ (Patterson et al. 1991) \\
\hline$D$ & Molecular diffusivity of $\mathrm{O}_{2}$ in seawater $\left(\mathrm{cm}^{2} / \mathrm{s}\right)$ & $2 \times 10^{-5}$ (Patterson et al. 1991) \\
\hline$u$ & Flow velocity $(\mathrm{cm} / \mathrm{s})$ & variable \\
\hline$h_{\mathrm{m}}$ & Mass-transfer coefficient (cm/s) & variable (light and flow dependent) \\
\hline$a$ and $b$ & Coefficients of relationship between Sh:Re (dimensionless) & Fig. 1 \\
\hline$P_{\mathrm{vs}}$ & $\begin{array}{l}\text { Oxygen concentration at tissue surface during maximum } \\
\text { photosynthesis }\left(\% \mathrm{O}_{2}\right)\end{array}$ & variable (light and flow dependent) \\
\hline$R_{\mathrm{vs}}$ & $\begin{array}{l}\text { Oxygen concentration at tissue surface during respiration in } \\
\text { darkness }\left(\% \mathrm{O}_{2}\right)\end{array}$ & variable (light and flow dependent) \\
\hline$P_{\mathrm{vf}}$ & $\mathrm{O}_{2}$ concentration within seawater $\left(\% \mathrm{O}_{2}\right)$ & see Methods: Modeling framework \\
\hline$P$ & $\mathrm{O}_{2}$ flux from tissue $\left(\% \mathrm{O}_{2} \mathrm{~cm}^{-2} \cdot \mathrm{s}^{-1}\right)$ & variable \\
\hline$P_{\text {day }}$ & Daily integrated energy acquisition $\left(\% \mathrm{O}_{2} \cdot \mathrm{cm}^{-2} \cdot \mathrm{d}^{-1}\right)$ & variable \\
\hline$x_{P}$ and $x_{R}$ & $\begin{array}{l}\text { Deviation of asymptotic oxygen tissue concentration from } \\
100 \% \text { during photosynthesis }\left(x_{P}\right) \text { and respiration }\left(x_{R}, \% \mathrm{O}_{2}\right)\end{array}$ & Table 2 \\
\hline$\alpha_{P}$ and $\alpha_{R}$ & $\begin{array}{l}\text { Rate at which } P_{\mathrm{vs}} \text { approaches saturation with increasing Re during } \\
\text { photosynthesis }\left(\alpha_{P}\right) \text { or respiration }\left(\alpha_{R}\right)\left(\% \mathrm{O}_{2} / \mathrm{Re}\right)\end{array}$ & Table 2 \\
\hline$\beta_{P}$ and $\beta_{R}$ & $\begin{array}{l}\text { Maximum }\left(\beta_{P}\right) \text { or minimum }\left(\beta_{R}\right) \text { tissue oxygen concentration as } \mathrm{Re} \\
\quad \text { approaches zero }\left(\% \mathrm{O}_{2}\right)\end{array}$ & Table 2 \\
\hline$E$ & Light intensity $\left(\mu \mathrm{mol}\right.$ photons $\left.\cdot \mathrm{m}^{-2} \cdot \mathrm{s}^{-1}\right)$ & variable \\
\hline$E_{K}$ & Subsaturation irradiance $\left(\mu \mathrm{mol}\right.$ photons $\left.\cdot \mathrm{m}^{-2} \cdot \mathrm{s}^{-1}\right)$ & 100 \\
\hline$E_{\max }$ & Maximum daily irradiance $\left(\mu \mathrm{mol}\right.$ photons $\left.\cdot \mathrm{m}^{-2} \cdot \mathrm{s}^{-1}\right)$ & variable \\
\hline
\end{tabular}

where $a$ and $b$ are empirically determined coefficients that depend upon organism shape and surface roughness. Analysis of the relationship between $\mathrm{Sh}$ and $\mathrm{Re}$ allows the effects on gas exchange of organism size and flow velocity to be investigated. This is achieved by rearranging Eqs. 2 and 3 to obtain an expression for the mass transfer coefficient, $h_{\mathrm{m}}$ :

$$
h_{\mathrm{m}}=\frac{a \operatorname{Re}^{b} D}{W}
$$

where $a, b, D$, and $W$ are as just defined (see Table 1). By definition, $h_{\mathrm{m}}$ summarizes the interaction of organism morphology with fluid motion (Patterson 1992). Therefore, combining this expression for $h_{\mathrm{m}}$ (Eq. 4) into a general gas exchange model allows the effects on photosynthesis of colony size, colony morphology and flow velocity to be investigated:

$$
P=h_{\mathrm{m}} A\left(P_{\mathrm{vs}}-P_{\mathrm{vf}}\right)
$$

where $P$ is the rate of gas exchange (in this case, photosynthetic oxygen flux), $h_{\mathrm{m}}$ is the mass transfer coefficient, $P_{\mathrm{vf}}$ and $P_{\mathrm{vs}}$ are the concentrations of gas in the fluid and at the photosynthesizing surface, respectively, and $A$ is the surface area.

Accurate quantification of the coefficients of the Sh:Re relationship ( $a$ and $b$ in Eqs. 3 and 4) is critical for analyses of the effects of flow on photosynthesis. Engineering theory provides estimates of these coefficients for regularly shaped, smooth structures such as cylinders and spheres (see Helmuth et al. 1997b). However, for rugose, irregular structures like corals, these parameters must be determined empirically. While several studies have explored the relationship between Sh and Re for corals, estimates of $a$ and $b$ based on live tissue measurements are only available for two species: Montastrea annularis (Patterson et al. 1991) and Pocillo- pora damicornis (Lesser et al. 1994). Other studies have instead explored mass-flux dynamics by measuring water evaporation from coral skeletons in a wind tunnel (e.g., Helmuth et al. $1997 a, b$ ), or the flux of calcium carbonate from plaster-covered skeletons (Falter et al. 2007).

In this study, we extended the general model outlined above in two ways. First, we improved on existing methods for calculating the mass transfer coefficient $\left(h_{\mathrm{m}}\right)$. Suitable equipment for measuring tissue-surface oxygen concentrations $\left(P_{\mathrm{vs}}\right)$ was only developed recently. For this reason, previous studies evaluated $h_{\mathrm{m}}$ by setting $P_{\mathrm{vs}}=0$ in darkness, and assuming $P_{\mathrm{vs}}$ is "at saturation" when colonies are photosynthesizing (Patterson and Sebens 1989, Patterson et al. 1991). However, recent studies have found tissue oxygen concentrations between $10 \%$ and $91 \%$ of saturation in darkness, and between $107 \%$ and $400 \%$ of saturation during photosynthesis (Shashar et al. 1993, Gardella and Edmunds 1999, Larkum et al. 2003). To allow for such variation in tissue oxygen concentrations, we calibrated the relationship between $h_{\mathrm{m}}$, flow, and colony size using simultaneous direct measurements of total oxygen flux from colonies of known surface area, oxygen concentration in the water column, and oxygen concentration at the tissue surface (see Photosynthesis experiments).

Second, we extended the general model (Eq. 5) to calculate daily energy acquisition $\left(P_{\text {day }}\right)$ from rates of photosynthesis integrated over the diurnal cycle, explicitly incorporating light intensity. Expressed in this way, Eq. 5 becomes

$$
P_{\text {day }}=\int_{t=0}^{24} h_{\mathrm{m}}(u, W)\left\{P_{\mathrm{vs}}[E(t), u]-P_{\mathrm{vf}}\right\} d t
$$

where the mass transfer coefficient $h_{\mathrm{m}}(u, W)$ is calibrated experimentally as outlined above. To incorporate the dependence of photosynthesis on light 
intensity, we allowed $P_{\mathrm{vs}}(E(t), u)$ to follow the hyperbolic tangent equation: as light intensity increases, $P_{\mathrm{vs}}$ rises from its minimum value in darkness $\left(R_{\mathrm{d}}\right)$ up to its saturated value at $P_{\max }$. Both $R_{\mathrm{d}}$ and $P_{\max }$ are dependent upon flow velocity, $u$ :

$$
P_{\mathrm{vs}}[E(t), u]=\left[P_{\max }(u)-R_{\mathrm{d}}(u)\right] \tanh \frac{E(t)}{E_{k}}+R_{\mathrm{d}}(u)
$$

For these analyses, we set $P_{\mathrm{vf}}$ as a constant, equal to the average value measured during our experiments. Finally, we allowed light intensity to vary over the day as a sine function defined by maximum daily irradiance $\left(E_{\max }\right)$, time of day $(t)$ and day length ( $L, 12$ hours):

$$
E(t)=E_{\max } \sin ^{2}\left(\frac{\pi t}{L}\right) .
$$

Due to time constraints during data collection, we were unable to obtain estimates of $E_{k}$ (light intensity at which photosynthesis is $75 \%$ of its maximum value). For many corals, estimates of $E_{k}$ lie between 50 and $400 \mu \mathrm{mol}$ photons $\cdot \mathrm{m}^{-2} \cdot \mathrm{s}^{-1}$ (Chalker et al. 1983, Anthony and Hoegh-Guldberg 2003a). We here assume a fixed value of $100 \mu \mathrm{mol}$ photons $\cdot \mathrm{m}^{-2} \cdot \mathrm{s}^{-1}$ as a baseline value suitable for low-light-acclimated corals. However, to confirm that our results are robust to this assumption, we explored the sensitivity of our model to the value of $E_{k}$.

\section{Study species and aquarium setup}

Experimental work for this study was conducted in May-June 2006 at One Tree Island (Great Barrier Reef [GBR], Australia, $23^{\circ} 28^{\prime} \mathrm{S}, 152^{\circ} 04^{\prime} \mathrm{E}$; see Plate 1). Data collection and model calibration was implemented for three species: Acropora nasuta (branching), Leptoria phrygia (mound-shaped), and Montipora foliosa (plating). These species are common on the GBR and occur across a range of light and flow conditions (Veron 2000).

For each species, 15-18 colonies measuring 15-20 cm in diameter, were collected from 4- and 9-m depths and maintained in a large aquarium $(200 \mathrm{~L})$ with continuous water exchange. Thermostat-controlled aquarium heaters maintained water temperature between $18^{\circ} \mathrm{C}$ and $20^{\circ} \mathrm{C}$, approximating water temperature in the field at the time of collecting $\left(19.4^{\circ} \mathrm{C}\right)$. Light and temperature within the tank were continuously monitored using Odyssey loggers (Odyphoto and Odytemp, Data Flow systems, Burnside Christchurch, New Zealand). Different light acclimation treatments were established by dividing the aquarium into high- and low-light regions (HL and LL, respectively) using shade cloth. Each treatment had 7-9 colonies per species allocated to it, with colonies from shallow depths placed under HL and colonies from deeper water under LL. During the experiments, average maximum irradiance in treatments was $520 \mu \mathrm{mol}$ photons $\cdot \mathrm{m}^{-2} \cdot \mathrm{s}^{-1}$ (HL) and $250 \mu \mathrm{mol}$ photons $\cdot \mathrm{m}^{-2} \cdot \mathrm{s}^{-1}(\mathrm{LL})$, which corresponds to depths of approximately $7 \mathrm{~m}$ and $14 \mathrm{~m}$ in the field, respectively (M. Hoogenboom, unpublished data). Colony surface area was determined by foil-wrapping (Marsh 1970).
For the mass flux measurements, we defined the characteristic dimension of colonies ( $W$, in centimeters) as length in the direction of flow, and calculated this length by photographing colonies using a fixed grid as a scale bar, and analyzing photos using ImageTool software (UTHSCSA, v2). ${ }^{2}$

\section{Photosynthesis experiments}

Respirometry.-Photosynthesis measurements were conducted using oxygen respirometry chambers. Unidirectional, recirculating flow was generated within these chambers using propellers driven by variable-speed $12-\mathrm{V}$ DC motors. This design allowed different flow speeds to be produced by varying the power input to the motors. Our analyses required the use of two different sizes of respirometry chambers: a single small (10-L) chamber was used to measure the Re:Sh relationship, and a set of four large (19.5-L) chambers was used to measure rates of photosynthesis and respiration across a wide range of flow speeds. Water flow within chambers was calibrated for all power settings using visual tracking of small, neutrally buoyant wooden beads. To do this, series of still images were captured from video footage of circulating particles, the positions of randomly chosen particles along the centerline of the chamber were overlaid in a time series, and the distance moved by each particle was calculated in both horizontal and vertical directions. Both flow speed and water turbulence can affect mass flux (e.g., Falter et al. 2007). Therefore, because chamber size can influence turbulence, we analyzed the relationship between flow speed and turbulence in the small and large chambers to verify that the flow regimes did not differ between chambers. To do this, we plotted the relationship between mean flow speed and the root mean square of the turbulent fluctuations in flow speed and compared the slopes of these relationships. These analyses confirmed that the flow characteristics of the two sizes of chambers were indeed consistent (see Appendix A for details).

Whole-colony rates of oxygen flux from live colonies were determined by continuously measuring oxygen concentration within chambers over a 45-minute measuring period. To do this, we used Clark-type oxygen electrodes connected to a signal-linearizing device (Cheshire Systems, Adelaide, Australia), and recorded using a datalogger (CR10X, Campbell-Scientific, Thuringowa Central, Australia). Tissue surface $\left(P_{\mathrm{vs}}\right)$ and free-stream $\left(P_{\mathrm{vf}}\right)$ oxygen concentrations were measured using oxygen micro-optodes (PreSens, Regensburg, Germany; $140 \mu \mathrm{m}$ thick), that were positioned using a micro-manipulator either in the water column well above the colony (measuring $P_{\mathrm{vf}}$ ) or directly at the tissue surface (measuring $P_{\mathrm{vs}}$ ). Optodes were connected to a single-channel fiber-optic oxygen meter (Microx TX, PreSens, Regensburg, Germany), with the signal

\footnotetext{
${ }^{2}\langle$ html://ddsdx.uthscsa.edu/dig/itdesc.html $\rangle$
} 


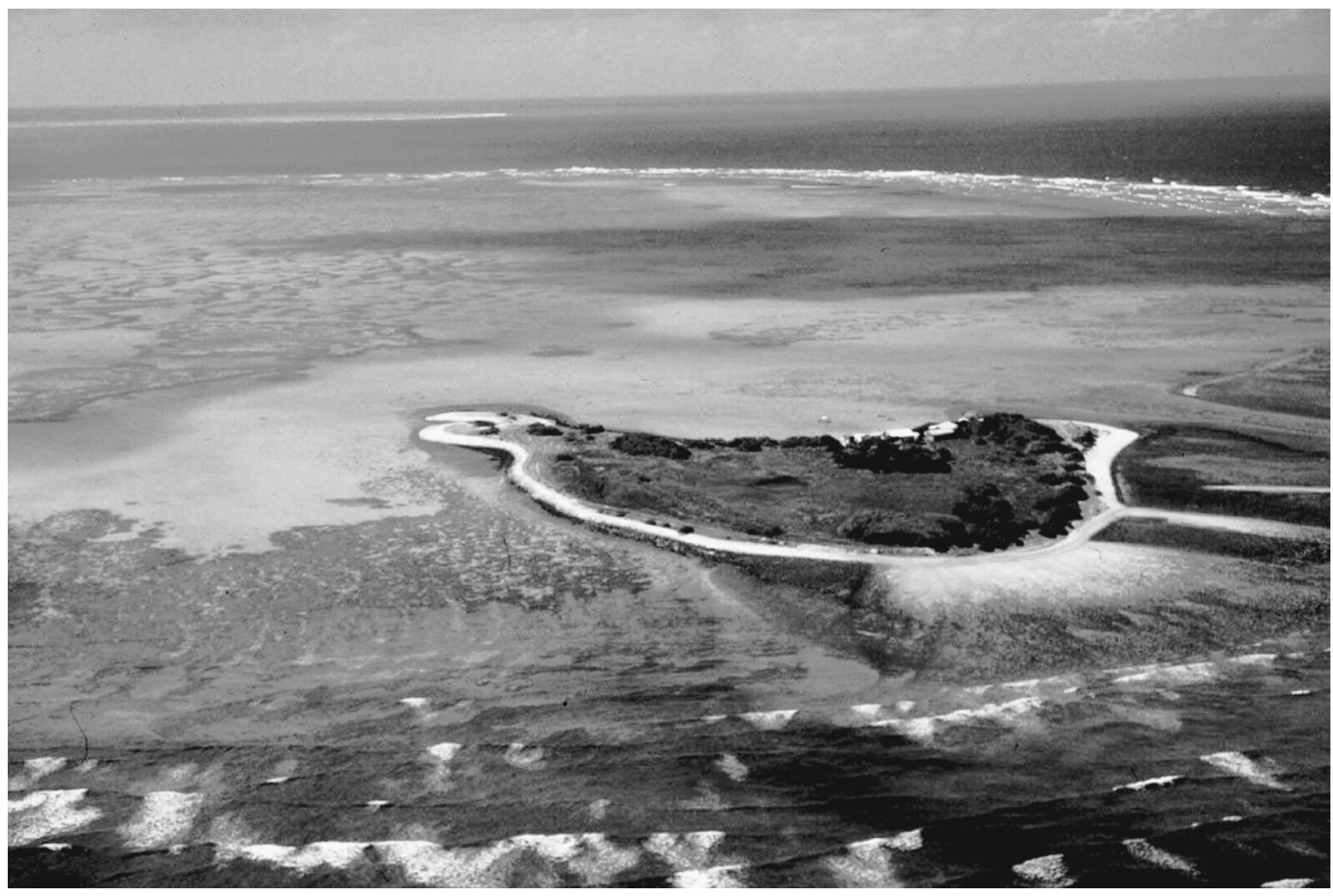

Plate 1. One Tree Island reef is located in the southern section of the Great Barrier Reef in Australia and has been a site of active research for over 40 years. The island is surrounded by an extensive and complex lagoon system. Environmental conditions, particularly light intensity and water flow velocity, vary strongly between exposed outer reef margins and protected positions within the lagoon. Photo credit: Michael Kingsford, courtesy of One Tree Island Research Station.

logged and monitored in real time (every three seconds) using a laptop computer. Following each measuring period, motors were turned off and chambers were flushed with fresh seawater. Oxygen electrodes and micro-optodes were calibrated immediately prior to and after respirometry runs, using seawater at $100 \% \mathrm{O}_{2}$ saturation, and nitrogen gas as a $0 \% \mathrm{O}_{2}$ baseline. Respirometry chambers were submerged in a $200-\mathrm{L}$ water jacket to ensure consistent temperature during measuring periods. In addition, water temperature and salinity were monitored twice daily to account for potential variation in oxygen solubility across subsequent days of data collection.

Reynolds: Sherwood relationship.-To calibrate the relationship between Reynolds and Sherwood number (Eq. 3), simultaneous measurements of (a) oxygen concentrations at the tissue surface, $P_{\mathrm{vs}}$ (b) free-stream oxygen concentrations, $P_{\mathrm{vf}}$, and (c) whole-colony rates of photosynthesis, were carried out in a single respirometry chamber (10-L volume). Photosynthesis assays were conducted at 2-3 flow speeds, for 3-4 colonies of each species from each light-acclimation treatment. These measurements were made at flow speeds between 2 and $10 \mathrm{~cm} / \mathrm{s}$, encompassing only those flow velocities over which mass flux is limited by gas diffusion (i.e., below $10 \mathrm{~cm} / \mathrm{s} ;$ Hurd 2000). For each colony, $P_{\mathrm{vs}}$ and $P_{\mathrm{vf}}$ were measured at 6-8 points on the colony surface, with the measurement for each point calculated as the average of 6 replicate measurements taken over a 20-s time period.

Using the simultaneous measurements of rates of photosynthesis and tissue-surface oxygen concentrations, we evaluated the mass transfer coefficient $\left(h_{\mathrm{m}}\right)$ as the ratio of average mass flux over the colony surface, $P$, to the (average) oxygen concentration gradient ( $P_{\mathrm{vs}}{ }^{-}$ $\left.P_{\mathrm{vf}}\right)$. Sh and Re were then determined from Eqs. 1 and 2 (see Table 1). The coefficients $a$ and $b$ of the Sh:Re relationship were estimated from linear regression of $\log _{10}$ values for these parameters using the software package Statistica (v7, StatSoft, Tulsa, Oklahoma, USA). To test for potential effects of photo-acclimatory state on this relationship, we estimated these coefficients separately for high- and low-light-acclimated colonies, and then used $t$ tests to determine whether the slopes of these relationships differed across light treatments.

Effects of flow and colony size on photosynthesis and respiration.-To calibrate the model over a greater range of colony sizes and flow speeds, additional measurements of whole-colony rates of photosynthesis and respiration were made for all corals at flows ranging 
between 6 and $38 \mathrm{~cm} / \mathrm{s}$. These values capture the range of flow velocities commonly experienced in reef environments (e.g., Sebens and Johnson 1991, Helmuth et al. 1997a). For these assays, measurements were made using the set of four large respirometry chambers. Each day of data collection (18 days in total), four colonies were selected at random, and maximum rates of photosynthesis $\left(P_{\max }\right)$ and dark-respiration $\left(R_{\mathrm{d}}\right)$ were measured in a darkened room, where the only light source was a set of $400-\mathrm{W}$ metal halide lamps (EYE, Tokyo, Japan). Using the procedure described in Respirometry above, measurements of $P_{\max }$ were carried out at 3-6 flow speeds between 11:00 hours and 16:00 hours, with colonies exposed to a constant irradiance of $720 \mu \mathrm{mol}$ photons $\cdot \mathrm{m}^{-2} \cdot \mathrm{s}^{-1}$ during this period. This irradiance was sufficient to saturate rates of photosynthesis for our corals (e.g., $>500 \mu \mathrm{mol}$ photons $\cdot \mathrm{m}^{-2} \cdot \mathrm{s}^{-1}$; see Chalker et al. 1983, Anthony and Hoegh-Guldberg $2003 a, b)$ without causing a decline in rates of photosynthesis due to photoinhibition (e.g., Hoogenboom et al. 2006). Following the photosynthesis measurements, colonies were rested in darkness for 1.5 hours with chambers continuously flushed with seawater. $R_{\mathrm{d}}$ was subsequently measured at 3-6 flow speeds between 17:30 and 22:30 hours. To control for possible photosynthesis and respiration of water-borne microorganisms, we conducted control (empty-chamber) runs at each flow speed, and subtracted the oxygen evolution/consumption by the water column from colony photosynthesis and respiration data.

Measurements of photosynthesis and respiration were used to account for a potential limitation of oxygen concentrations within coral tissue by photosynthetic activity (i.e., enzyme processing) rather than by diffusion of gases from tissue. To do this, we used the speciesspecific calibrations of the dependence of $h_{\mathrm{m}}$ on $u$ and $W$ (the $\mathrm{Sh}: \mathrm{Re}$ relationship) to calculate tissue oxygen concentrations corresponding to the measurements of $P_{\text {max }}$ and $R_{\mathrm{d}}$ for each colony. We then expressed tissue oxygen concentration as a percentage relative to the water column during photosynthesis $\left(P_{\mathrm{vs}} \div P_{\mathrm{vf}} \times 100\right)$ and respiration $\left(R_{\mathrm{vs}} \div P_{\mathrm{vf}} \times 100\right)$. We then fitted an equation of the following form to $P_{\mathrm{vs}}$ and $R_{\mathrm{vs}}$ data for each species:

$$
\% \mathrm{O}_{2}=(100+x)+\beta \exp ^{-\alpha \mathrm{Re}}
$$

where $\beta$ is the percentage by which $\mathrm{O}_{2}$ at the tissue surface deviates from saturation at $\mathrm{Re}=0, \alpha$ is the rate at which $\mathrm{O}_{2}$ saturation changes with increasing $\mathrm{Re}$, and $x$ allows for an asymptote at values different from $100 \%$.

\section{Tissue quality and reproductive output}

As an independent test of model performance, we compared estimates of tissue quality and reproductive output from colonies sampled in the field with model predictions of energy acquisition. To do this, we established 10 sites in and around One Tree Island lagoon. These sites were stratified to encompass a range of light and flow conditions, and were spread between the windward and leeward sides of the reef exterior, as well as within the lagoon itself. At each site, light and temperature profiles were measured during November 2005 and 2006 using Odyssey loggers and sensors (see Study species and aquarium setup). Water flow was measured using the plaster-dissolution technique of Fulton and Bellwood (2005). This technique relates the dissolution of spherical gypsum balls to average flow velocity within a flume with a similar design to our flow chambers, allowing us to reliably equate chamber and field flow velocities. Flow measurements were taken at all sites over a period of 10 days during November 2006, and additionally during May/June 2006 at sites within the lagoon. During each of 5 deployments of 24-48 hour duration, three replicate gypsum balls were affixed to individual stakes $15 \mathrm{~cm}$ above the substratum at each monitoring site. Gypsum balls were dried to constant mass prior to and after deployment.

During November 2005, we collected four fragments measuring 3-4 cm diameter from 6 colonies of Acropora nasuta and Leptoria phrygia at nine sites (these species were absent from one site), and four fragments from 2-6 colonies of Montipora foliosa from eight sites (this species was absent from two sites and less abundant at all sites). In order to measure colony diameter, sampled colonies were photographed in the field with a ruler as a scale bar. Two fragments were immediately frozen for subsequent analysis of total protein concentration as a proxy for tissue biomass. Total protein was measured using Bio-Rad's total protein kit and protocol (Bio-Rad Laboratories, Hercules, California, USA). Standards of known protein concentration between 0 and $2 \mathrm{mg} / \mathrm{mL}$ were prepared using bovine-serum-albumen (BSA, Sigma Chemicals, Perth, Australia). We then solubilized tissue from each fragment (two replicates per colony) using two successive one-hour digestions in $1 \mathrm{~mol} / \mathrm{L}$ $\mathrm{NaOH}$ held at $90^{\circ} \mathrm{C}$. We then combined $100 \mu \mathrm{L}$ of protein solution with $5 \mathrm{~mL}$ of protein dye reagent and determined absorbance at $595 \mathrm{~nm}$ spectophotometrically. Finally, total protein of samples was determined by comparison with the absorbance of the calibration standards. For the estimates of reproductive output, the remaining fragments from each colony were fixed in $10 \%$ formalin in seawater and later decalcified in $10 \%$ formic acid. Reproductive output was then determined by counting the number of eggs in each of 12-15 polyps per fragment for Acropora nasuta and Montipora foliosa. Corallites in Leptoria phrygia form valleys in place of discrete polyp units. Therefore, for this species we counted eggs contained in each of 12-15 mesenteries (i.e., tissue containing reproductive organs). As for the protein analyses, egg counts were conducted for two replicate fragments per colony.

\section{Model analyses}

To predict the niche for each species, we evaluated Eq. 6 at maximum daily irradiance values between 50 and 
$1800 \mu \mathrm{mol}$ photons $\cdot \mathrm{m}^{-2} \cdot \mathrm{s}^{-1}$ and at average water flow velocities between 2 and $40 \mathrm{~cm} / \mathrm{s}$. Subsequently, for each species, at all combinations of light and flow conditions, we calculated daily photosynthetic oxygen evolution $\left(P_{\text {day }}\right)$ and daily respiratory costs $\left(R_{\text {day }}\right)$, and measured the niche as the conditions where the ratio of daily photosynthesis to respiration $(\mathrm{P}: \mathrm{R}$ ratio) $>1$. We converted oxygen flux to carbon equivalents based on molar masses, as $P_{\text {day }}=$ mol $\mathrm{O}_{2}$ produced $\cdot 12 / \mathrm{PQ}$ and $R_{\text {day }}=\mathrm{mol} \mathrm{O}_{2}$ consumed $\cdot 12 \cdot \mathrm{RQ}$ (Anthony and Fabricius 2000) where PQ and RQ are photosynthetic and respiratory quotients ( 1.1 and 0.8 , respectively; Muscatine et al. 1981).

To explore the association between measured tissue properties and energetics calculated by our model, we predicted energy acquisition for sampled colonies based on their diameter, average light and flow conditions at collection sites, and the calibrated mass-transfer model for each species. Uncertainty in parameter estimates for mass fluxes was incorporated using a Monte Carlo simulation technique. To do this, we made 1000 replicate calculations of energy acquisition for each colony, using parameters drawn randomly from multivariate Gaussian distributions based on the variance-covariance matrices of the fitted models. We then correlated predicted P:R ratio (averaged over the 1000 iterations) with both protein content and reproductive output. Spearman's rank correlation was used because our reproduction data contains tied values.

\section{Results}

\section{Mass flux relationships}

We observed the expected power law relationship between Sherwood and Reynolds numbers for all species (Fig. 1). That is, with increasing Re the degree to which mass flux was enhanced by advection, relative to that possible through diffusion, also increased. The rate of increase in Sh with Re was highest for Montipora foliosa $(b=1.3)$, followed by Acropora nasuta and Leptoria phrygia ( $b=0.85$ and 0.74, respectively; see Fig. 1). Enhancement of mass flux due to flow/colony size was consistent across light-acclimation treatments for all three species. Best-fit values of $b$ (Fig. 1) for high-light and low-light-acclimated colonies of each species were not significantly different ( $t$ test; $A$. nasuta, $t_{2,0.05}(\mathrm{df}=$ 11) $=0.9, P=0.4 ;$ L phrygia, $t_{2,0.05}(\mathrm{df}=13)=1.8, P=$ $0.1 ; M$. foliosa, $\left.t_{2,0.05}(\mathrm{df}=9)=1.4, P=0.2\right)$. In other words, we found no evidence that photoacclimatory state influenced mass flux dynamics for our study species.

\section{Diffusion limitation of photosynthesis and respiration}

For all three species, tissue surface oxygen concentrations were not affected by increasing colony size or water flow velocity (Reynolds number) over at least the upper half of the range of conditions tested (Fig. 2). The average standing stock of $\mathrm{O}_{2}$ at the tissue surface was always higher than ambient when colonies were
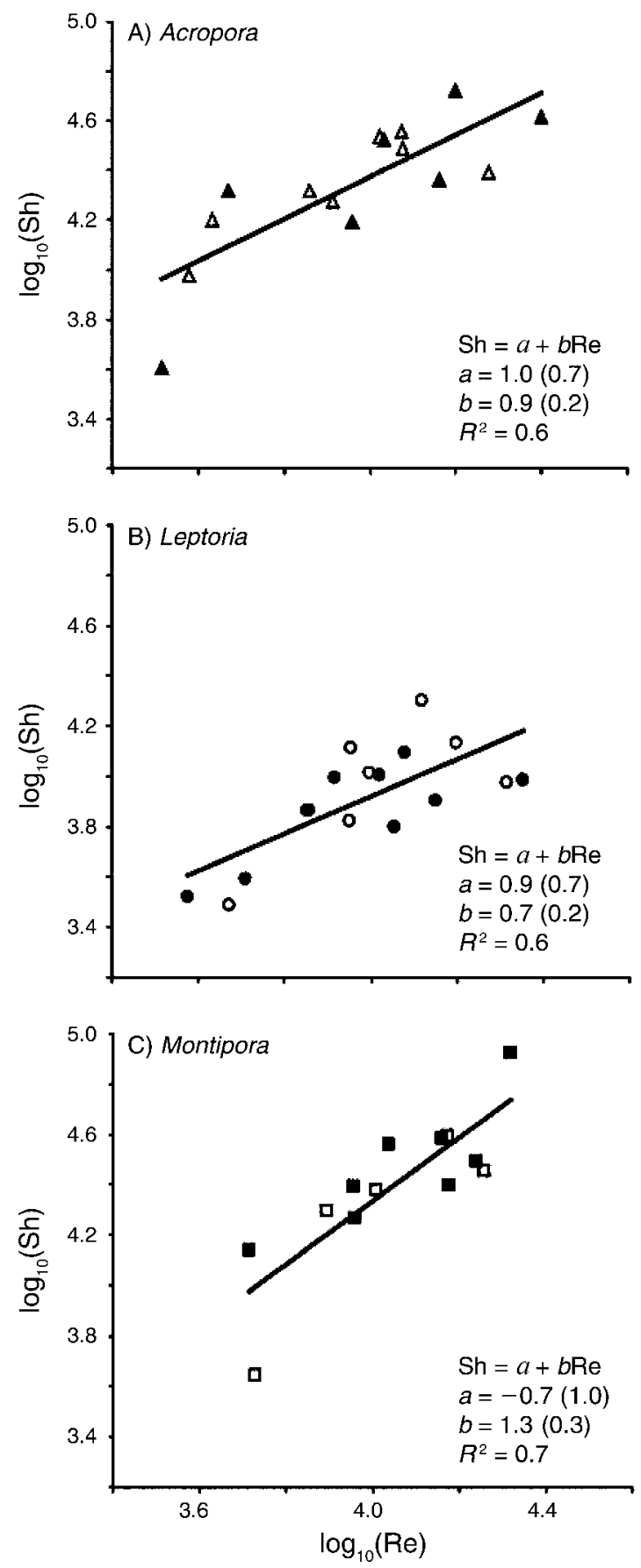

FIG. 1. Sherwood (Sh) vs. Reynolds (Re) relationship for colonies of (A) Acropora nasuta, (B) Leptoria phrygia, and (C) Montipora foliosa acclimated to high light levels (open symbols) and low light levels (solid symbols). Sh indicates how strongly mass flux is enhanced by direct transfer relative to the flux due to diffusion (Eq. 2). Re summarizes the ratio of inertial to viscous forces of a fluid as it moves over a surface (Eq. 1). The coefficients $a$ and $b$ (Eq. 3) describe how $\log (\mathrm{Sh})$ scales with $\log (\operatorname{Re})$, where $a$ is the $y$ intercept and $b$ is the slope of this relationship. Estimates of $a$ and $b$ for each species were determined using linear regression; numbers in parentheses are standard errors. Data are $\log _{10}$-transformed values calculated for individual colonies at different flow speeds. Regression parameters are presented within panels. 

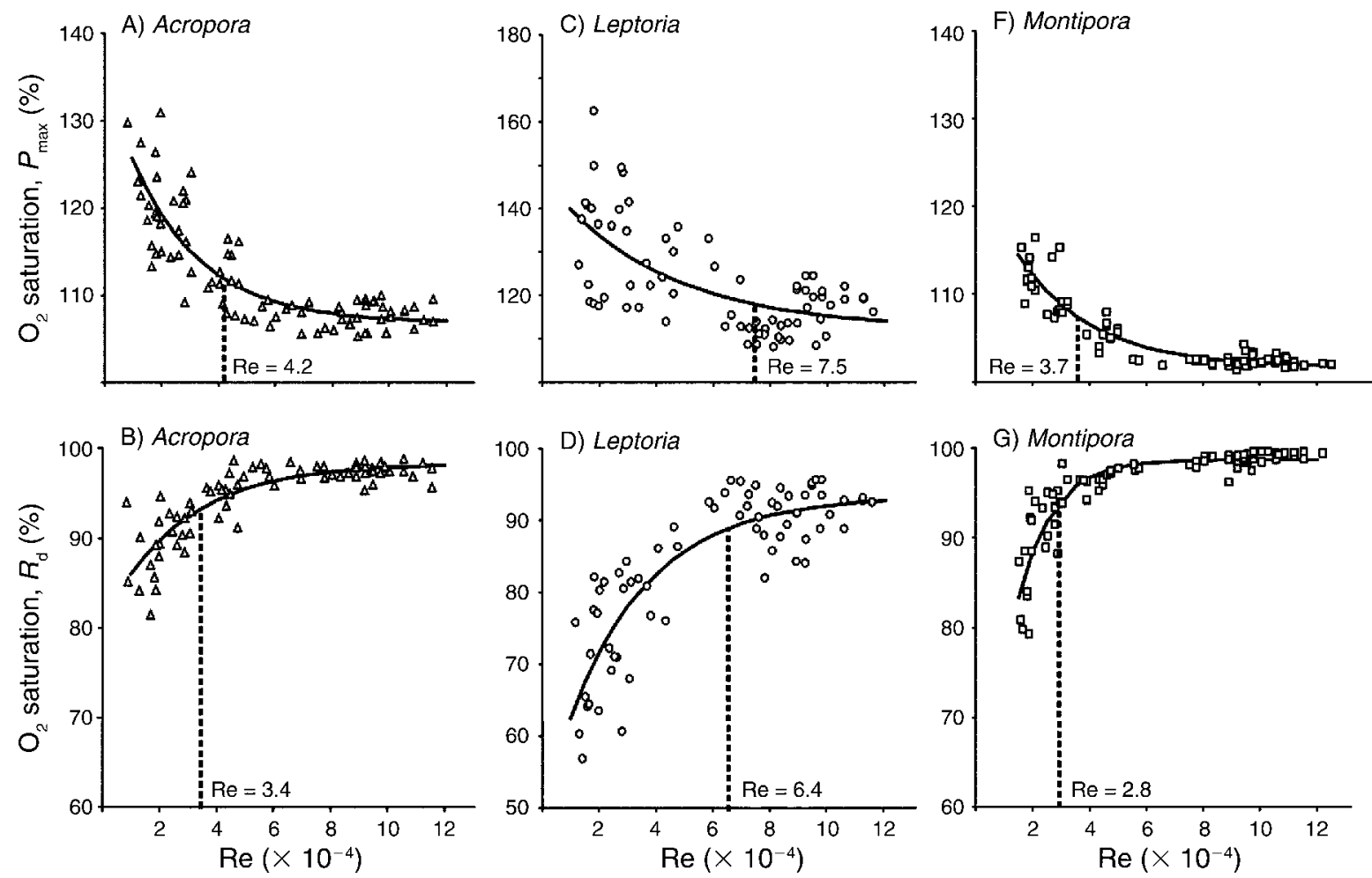

FIG. 2. Tissue surface oxygen concentration, expressed as a percentage of dissolved oxygen concentration in seawater, for Acropora nasuta (triangles), Leptoria phrygia (circles), and Montipora foliosa (squares) during (A, C, E) photosynthesis and (B, D, F) respiration. Data points are from measurements of maximum rates of photosynthesis $\left(P_{\max }\right)$ and dark respiration $\left(R_{\mathrm{d}}\right)$ for colonies at different flow speeds, taking into account the relationship between flow and mass transfer. Vertical dashed lines represent Re at which oxygen concentrations are $95 \%$ of their asymptotic value. Note that all Re values have been multiplied by $10^{-4}$ (e.g., the number "6" on the $x$-axes represents 60000 ).

photosynthesizing, and always less than ambient when colonies were respiring. That is, the fitted parameter $x$ (Eq. 9) was significantly different from zero in all cases (Table 2), with the magnitude of these differences highest for L. phrygia followed by A. nasuta and then M. foliosa. The value of Re at which oxygen concentration at the tissue surface reached $95 \%$ of its saturated value (dashed lines in Fig. 2) varied between species, and between photosynthesizing compared with respiring colonies. For all three species, as Reynolds number increased from low values, tissue oxygen concentrations reached saturation more rapidly during respiration compared with photosynthesis $\left(\alpha_{P}>\alpha_{R}\right.$ for $M$. foliosa and $L$. phrygia; Table 2 ), and thus were approximately constant over intermediate and large Reynolds numbers (Fig. 2). This means that respiration was more sensitive to Reynolds number when Reynolds numbers were low, but photosynthesis was more sensitive for intermediate and large Reynolds numbers. Although the differences in the parameters describing the shapes of the photosynthesis and respiration responses appear small in magnitude, such differences have a large influence on the shape of the niche (see Discussion).

\section{Tissue quality and reproductive output}

Model predictions of daily energy acquisition were positively correlated with tissue biomass (total protein) and reproductive output (eggs per polyp/mesentery) for

TABLE 2. Best-fit parameter estimates describing variation in tissue oxygen concentration with increasing Reynolds number (Re) during photosynthesis $\left(P_{\max }\right)$ and respiration $\left(R_{\mathrm{d}}\right)$ for colonies of Acropora nasuta, Montipora foliosa, and Leptoria phrygia.

\begin{tabular}{|c|c|c|c|c|c|c|c|c|}
\hline \multirow[b]{2}{*}{ Species } & \multicolumn{4}{|c|}{$P_{\max }$ parameter estimate $( \pm \mathrm{SE})$} & \multicolumn{4}{|c|}{$R_{\mathrm{d}}$ parameter estimate $( \pm \mathrm{SE})$} \\
\hline & $R^{2}$ & $x_{P}$ & $\alpha_{P}$ & $\beta_{P}$ & $R^{2}$ & $x_{R}$ & $\alpha_{R}$ & $\beta_{R}$ \\
\hline A. nasuta & 0.75 & $6.8(0.8)^{*}$ & $0.41(0.07)^{*}$ & $28(3.2)^{*}$ & 0.73 & $-1.7(0.64)^{*}$ & $0.36(0.07)^{*}$ & $-18(1.9)^{*}$ \\
\hline M. foliosa & 0.56 & $1.7(0.39)^{*}$ & $0.39(0.06)^{*}$ & $23(2.5)^{*}$ & 0.79 & $-1.4(0.35)^{*}$ & $0.81(0.11)^{*}$ & $-52(11)^{*}$ \\
\hline L. phrygia & 0.42 & $12(6)^{*}$ & $0.25(0.15)$ & $35(6)^{*}$ & 0.74 & $-6.7(1.9)^{*}$ & $0.35(0.1)^{*}$ & $-44(6)^{*}$ \\
\hline
\end{tabular}

$* P<0.05$. 

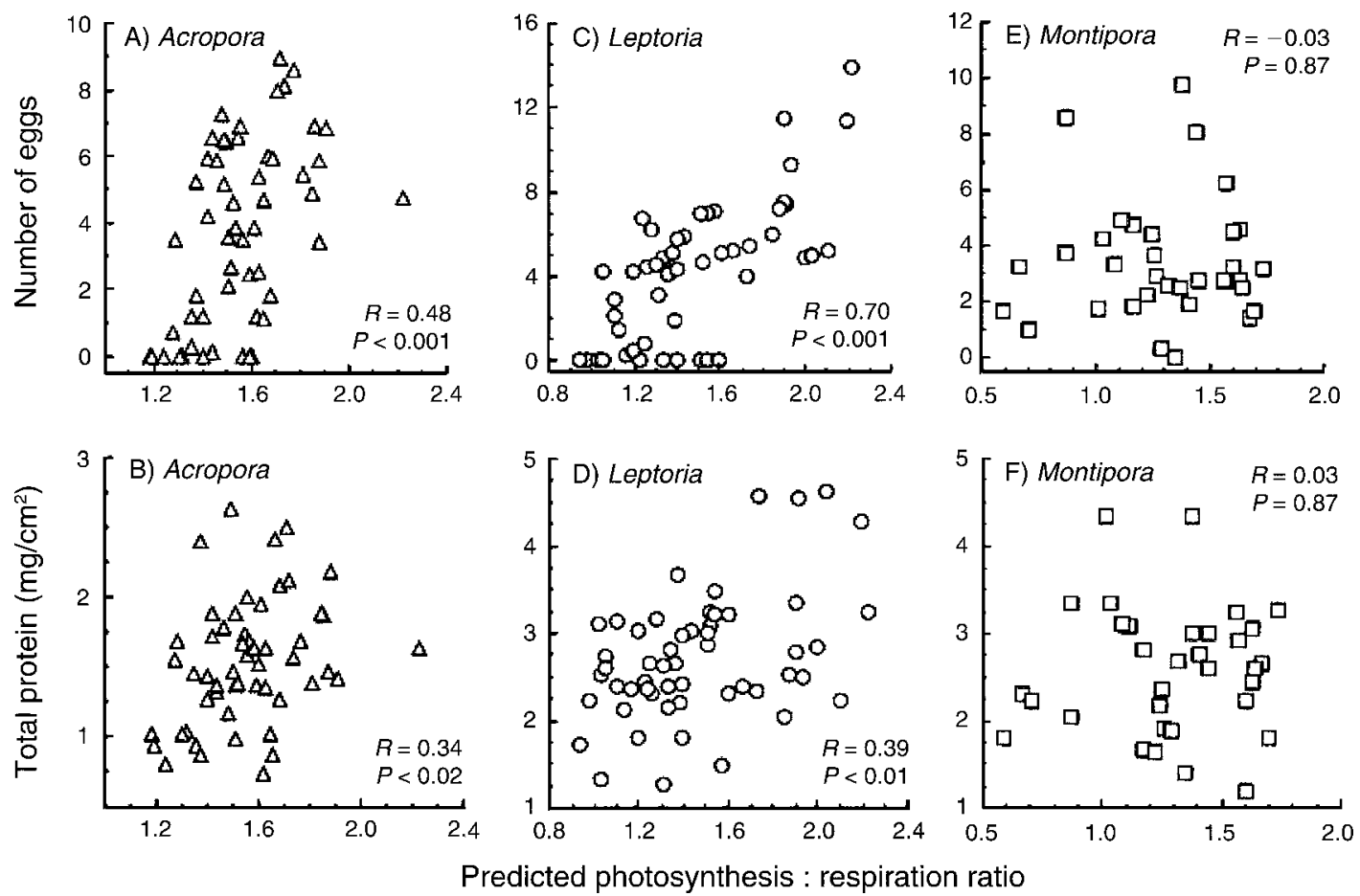

FIG. 3. Correlations between predicted energy acquisition with reproductive output (no. eggs) and tissue biomass (total protein) for colonies of Acropora nasuta (triangles), Leptoria phrygia (circles), and Montipora foliosa (squares). Spearman's rank correlations $(R)$ are shown together with significance level. Points represent photosynthesis : respiration ratios averaged over 1000 Monte Carlo simulations.

both A. nasuta and L. phrygia (Fig. 3). Conversely, for M. foliosa, the model did not capture variation in tissue properties observed in the field. For this species, tissue quality varied between colonies, but this variation was uncorrelated with energy acquisition predicted by the model. Furthermore, the mechanistic model based on the combined effects of light and flow on photosynthesis and respiration was a much better overall predictor of tissue properties than multiple regression models incorporating these two variables (Appendix B). Specifically, multiple regressions were nonsignificant in all cases but one, and, for the one exception, parameter estimates indicated a negative relationship between tissue biomass and water flow, opposite to what one would expect given that flow enhances flux of photosynthetic gases by reducing diffusive boundary layers.

\section{Niche width: energy acquisition}

The influence of light intensity and water flow velocity on daily energy acquisition differed among our study species, and was variably influenced by colony size (Fig. 4). In general, small colonies of each species had a positive energy balance across a narrower range of conditions than larger colonies (Fig. 4). Of the species considered here, the niche of $A$. nasuta was the least sensitive to flow and colony size. For this species, niche size increased only slightly with colony size, due to an increase in the range of light conditions tolerable under high-flow conditions for large colonies (Fig. 4A, B). For L. phrygia, the size of the niche increased with colony size to a much greater extent (Fig. 4C, D). The model predicted that small colonies of L. phrygia should be restricted to habitats of high light and high flow, but for large colonies, the region of positive energy balance expanded to encompass regions of lower light and/or flow. Energy balance for $M$. foliosa responded similarly to an increase in colony size to that of L. phrygia, except that larger colonies were less able to maintain positive energy balance for combinations of high flow and low light than small colonies were (Fig. 4E, F).

Mechanistically, the differences between species were driven by the magnitudes of the differences in tissue oxygen between photosynthesizing and respiring colonies. For $A$. nasuta, photosynthetic oxygen fluxes were greater than respiratory fluxes at low Reynolds numbers (Re), but the opposite was true for L. phrygia and $M$. foliosa (see Table 2). This meant that colonies of $A$. nasuta that were small and/or exposed to low-flow conditions (low Re) had a positive energy balance, whereas energy acquisition for small colonies of $L$. phrygia and M. foliosa was sensitive to the relationship between tissue oxygen and Re. Results also indicated that, for large colonies of M. foliosa and L. phrygia, high-flow conditions were only tolerable if irradiance levels were also high (Fig. 4D, F). For these two species, rates of photosynthesis at high Re were only slightly 


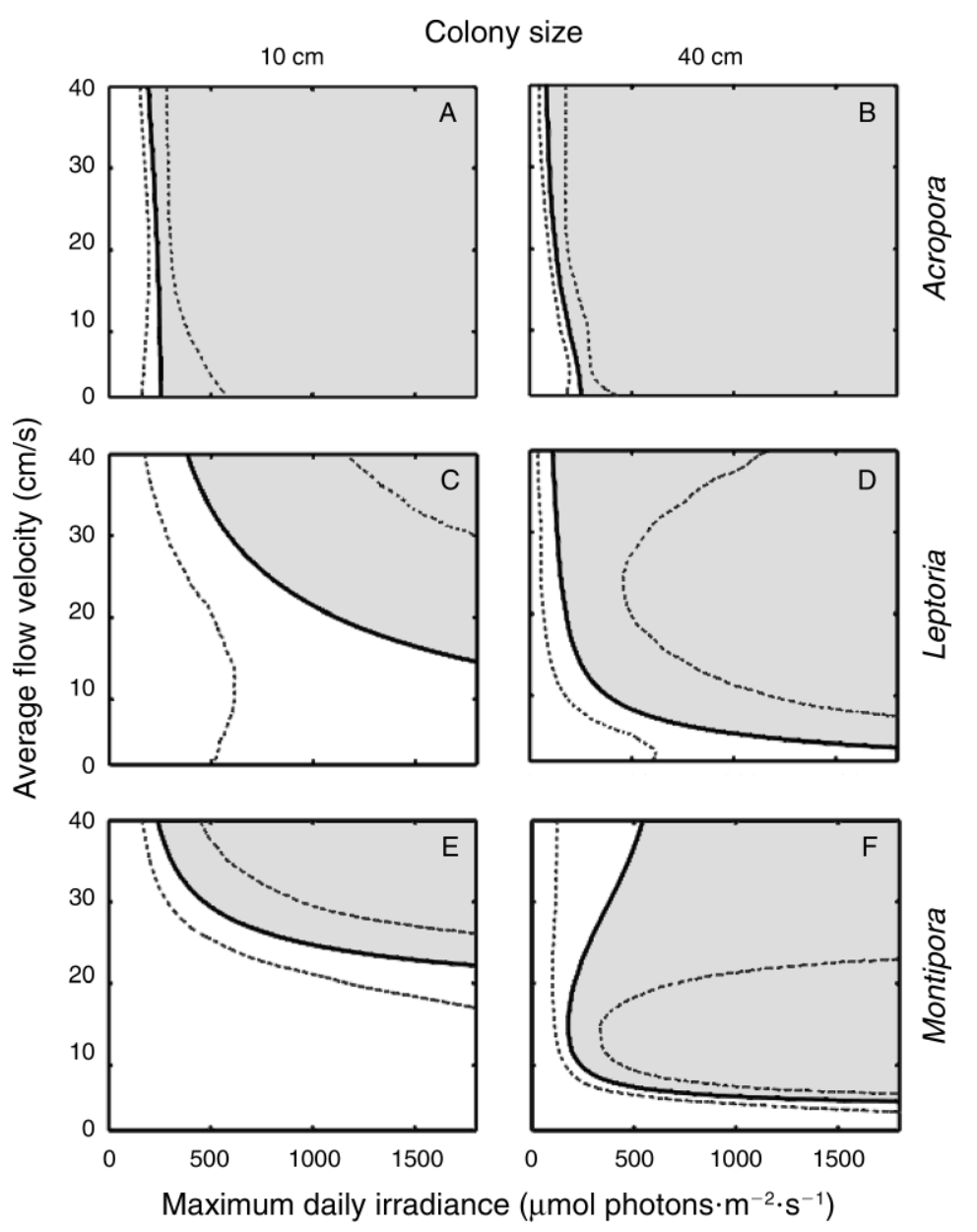

FIG. 4. Energetic niche dimensions for $10 \mathrm{~cm}$ and $40 \mathrm{~cm}$ diameter colonies of: (top row) Acropora nasuta, (middle row) Leptoria phrygia, and (bottom row) Montipora foliosa along gradients of light intensity ( $x$-axis) and flow velocity ( $y$-axis. Lines represent mean contours (solid lines) of positive energy acquisition (daily photosynthesis $>$ respiration, represented by the shaded region of the individual panels). Dashed lines represent 95\% confidence intervals generated from 1000 Monte Carlo simulations.

greater than rates of respiration. This meant that, unless light levels were high over most of the day, at high flow there were some combinations of parameter values for which energy acquisition by large colonies of $M$. foliosa and L. phrygia was less than maintenance costs.

As mentioned (see Mass flux relationships above), we found no evidence that photo-acclimatory state influenced gas diffusion dynamics for any of our study species. However, our light-acclimation irradiances did not include irradiances as high as those that might be observed in shallow, clear waters on sunny days. Therefore, to test how acclimation to high light influenced niche boundaries, we recalculated energy acquisition varying tissue oxygen concentrations $\left(P_{\mathrm{vs}}\right.$, $R_{\mathrm{vs}}$ ) to capture the essential components of photoacclimation to high light: namely increased oxygen production and consumption (Appendix C). These simulations revealed that the niche was insensitive to light-acclimation over a broad range of parameter combinations. However, the niche of high-light-acclimated colonies of each species was reduced, and shifted toward the high-light/high-flow area of the environmental gradient for A. nasuta and L. phrygia and toward the high-light/intermediate-flow region for $M$. foliosa (Appendix C). Overall, this indicates that the niche boundaries calculated by our model are robust over much of the realistic range of light conditions, but may overestimate energy acquisition in very high-light habitats.

\section{Discussion}

This study establishes a quantitative link between metabolic rates and the dominant environmental gradients on coral reefs (light intensity and water flow), enabling prediction of the conditions under which a positive energy balance is possible. Our analyses demonstrate that effects of natural variation in light and flow conditions on photosynthetic energy acquisition strongly influence tissue biomass and reproductive 
output. In addition, the mechanistic framework developed in this study identifies important ecological implications of variation in physiology. First, due to its higher photosynthetic capacity, the branching coral $A$. nasuta has a positive energy balance over a wider range of conditions than L. phrygia and $M$. foliosa. Second, niche size increases with colony size: larger colonies of all three species have a positive energy balance over a greater range of conditions because photosynthesis is more strongly enhanced by changes in colony size and flow (Reynolds number, Re) than respiration is. Finally, the influence of flow on energetics is variable across the light gradient. The synergistic effects of light and flow influence performance in a way that is not monotonically related to the effects of either of these variables individually, or together. Overall, these results indicate that the process-based model captures nonlinear interactions between light and flow that are unlikely to be captured with regression-based approaches. This highlights the importance of accounting for the interaction of these variables in a mechanistic framework.

\section{Mass flux models}

Our analyses confirm the utility of general mass flux models (Patterson et al. 1991, Patterson 1992). An additional advantage to such models is that, once the mass transfer coefficient ( $h_{\mathrm{m}}$, Eq. 4 ) has been evaluated for a given species, the same equations can be used to calculate the uptake and/or release of other solutes if the solubility of these molecules is known (e.g., $\mathrm{NO}_{3}$ and $\mathrm{PO}_{4}$; Sanford and Crawford 2000). Therefore, the models developed here could be extended to consider how colony growth and calcification may respond to gradients of water flow velocity, and how changes in the solubility of calcium and carbonate ions may affect this process (e.g., in response to ocean acidification; HoeghGuldberg et al. 2007).

Our results reveal that small changes in the relationships between environmental gradients and different physiological processes (e.g., photosynthesis vs. respiration) can have a strong effect on the niche. This study indicates that respiration becomes limited by oxygen consumption within tissue at lower Re than does oxygen evolution during photosynthesis. In other words, flow stops affecting respiration before it stops affecting photosynthesis. Although the magnitude of the difference in the values of Re at which this occurs is small, the consistency of this pattern across three species suggests that flow enhancement of photosynthesis over a greater range of flow conditions compared with respiration may be a general phenomenon.

This observation could potentially be explained by differences in the diffusion of $\mathrm{CO}_{2}$ compared with $\mathrm{O}_{2}$, where the former substrate may be a limiting factor for rates of photosynthesis, but not respiration (Carpenter and Williams 2007). This highlights an underlying assumption of the model: that efflux of oxygen during photosynthesis is linearly related to influx of carbon dioxide for carbon fixation. This assumption is supported by experimental evidence that boundary layer resistance to different molecules decreases in parallel with increasing flow (Koch 1994), and that flow has the same effect on photosynthesis when measured by changes in dissolved organic carbon compared with dissolved oxygen (Carpenter and Williams 2007). Therefore, boundary layer properties are not likely to be responsible for the differences in flow effects on respiration compared with photosynthesis. A more likely explanation is that this phenomenon is driven by spatial segregation in the sites of oxygen production and respiration within tissue. During respiration, oxygen is consumed by both coral (host) tissue as well as by symbionts. During photosynthesis, however, oxygen production only occurs in symbionts. Consequently, all oxygen evolved during photosynthesis must pass through tissue before it reaches the diffusive boundary layer (and $\mathrm{CO}_{2}$ must diffuse likewise in reverse). The net effect of this is an additional impediment to oxygen efflux during photosynthesis compared with oxygen use during respiration. This would cause photosynthesis to reach saturation more slowly as flow increases, thereby extending the range of flow velocities over which mass flux is enhanced.

\section{Predictive accuracy of the niche model}

Despite a robust characterization of the physiological mechanisms underlying photosynthetic energy acquisition for our study species, the combination of uncertainties in parameter estimates meant that the $95 \%$ confidence interval of energy balance contours was in some cases quite large. Niche boundary predictions (area between the dashed lines in Fig. 4) were most precise for $A$. nasuta, and most variable for small colonies of L. phrygia and large colonies of $M$. foliosa. Greater uncertainty in niche contours for the latter two species was due to higher between-colony variance in oxygen production and consumption (e.g., Fig. 2C-G) and corresponding uncertainty in the parameters of the relationships between tissue oxygen concentrations and Re (Table 2). Despite uncertainty about the exact position of the niche boundary, the model identifies some important general trends. Niche size increases with colony size; decreasing light availability leads to a narrowing of the flow conditions that allow a positive energy balance for large colonies of L. phyrgia and $M$. foliosa; and $A$. nasuta has a positive energy balance over a broader range of environmental conditions compared to our other study species.

Energy acquisition calculated by the model proved to be a statistically significant predictor of both tissue biomass and reproductive output for two of the three study species (A. nasuta and L. phrygia). However, the model did not capture variation in these properties for M. foliosa. We believe that there are three main reasons why this occurred. First, $M$. foliosa has a laminar 
growth form, and all sampled colonies grew approximately flat along the substratum. However, our field measurements of flow velocity were taken $15 \mathrm{~cm}$ above the substratum, a typical height for colonies of $A$. nasuta and L. phyrgia. Due to small-scale topographical differences, water flow at the substratum is highly variable within sites (Carpenter and Williams 1993), and flow over M. foliosa colonies may differ substantially from the measured values. Second, due to its horizontal growth form, $M$. foliosa may be more strongly influenced by interspecific competition (i.e., by overtopping; e.g., Stimson 1985), or by other benthosassociated processes such as instability and bioerosion. These factors would influence tissue quality for this species (e.g., due to damage; Ward 1995), but are not accounted for in the physiological model.

The third possibility is that heterotrophic feeding may make a larger contribution to the energy budget of $M$. foliosa than for our other study species. Under normal conditions (such as those investigated here), heterotrophic feeding provides only a small fraction of total energy acquisition (Anthony and Fabricius 2000, Grottoli et al. 2006). Moreover, a high capacity for heterotrophy is particularly unexpected for $M$. foliosa because enhanced particle feeding is generally associated with large polyp size (Porter 1976), whereas Montipora have very small polyps (Veron 2000). Nevertheless, recent experimental work indicates that heterotrophy plays a greater role in coral energetics than previously believed. Studies have shown that calcification rates may be $50-75 \%$ higher in corals fed with zooplankton (Houlbreque et al. 2003), and that overall growth rates may double with feeding (Miller 1995). For Montipora, a surprisingly high capacity for heterotrophy has been demonstrated. For instance, Grottoli et al. (2006) showed that, following a bleaching event that strongly reduced photosynthesis, a Montipora species was able to up-regulate heterotrophic feeding to a level that provided sufficient carbon to meet daily maintenance costs. A greater reliance on heterotrophic feeding would explain the lack of agreement between model predictions of energy acquisition and performance of Montipora foliosa in the field.

\section{Effect of colony size on predicted niche dimensions}

For all three species considered here, the niche model predicts that large colonies have a positive energy balance over a broader range of light and flow conditions than small colonies. In other words, niche size increases with colony size, mainly through an expansion of the tolerable flow conditions at a given light intensity. From a physiological basis, this result is surprising, particularly in light of the well-known allometric scaling of metabolism with body size in many organisms (West et al. 1997). Moreover, there is evidence that corals reduce their rates of photosynthesis and particle capture per unit surface area with increasing colony size (Jokiel and Morrisey 1986, Kim and Lasker
1998). Both of these factors indicate that the conditions allowing a positive energy balance should decrease as coral colonies grew larger. On the other hand, in agreement with our findings, Elahi and Edmunds (2007) demonstrated a positive effect of colony size on energy balance that was driven by greater enhancement of rates of photosynthesis compared with respiration. Furthermore, long-term monitoring of small colonies from several coral genera has also shown positive effects of colony size on growth rates (Edmunds 2006). Collectively, these findings suggest that different rules govern the scaling of metabolism with body size for modular compared with unitary organisms.

More broadly, these findings indicate that the establishment of small compared to large colonies strongly structures the habitat distributions of corals. Although few studies have compared the conditions that allow survival of adults and juveniles of sessile taxa (i.e., large compared with small coral colonies), there is some evidence for rain forest plants that juveniles occupy a broader range of habitats than adults (Webb and Peart 2000, Jones et al. 2007). Such a decrease in niche size with body size for plants differs from the pattern observed in this study. At present, we do not have sufficient evidence to support a discussion of these differences. However, our results suggest that energy balance at small colony size limits species distributions, regardless of the potential distribution of large colonies.

\section{The niche}

The utility of the niche as an ecological concept has been a subject of debate, particularly with respect to the various ways of measuring and defining a species' niche (e.g., Chase and Leibold 2003, Kearney 2006). In this study, we have focused upon identifying the range of physical (light and flow) conditions under which different coral species have sufficient energy acquisition for survival, growth, and reproduction. Undoubtedly, biotic interactions such as competition and predation also influence coral performance under natural conditions. However, the statistically significant correlations between model predictions of energy balance and measurements of tissue biomass and reproduction indicate that such biotic factors are of secondary importance to environmental factors as determinants of colony condition, at least for two of our study species (A. nasuta and L. phrygia).

Because the results presented here focus on colony energetics and condition, they shed light on how the energetic capacity for coral persistence, and the production of offspring, will vary along environmental gradients. However, our approach does not explicitly consider possible effects of disturbance events (e.g., bleaching, cyclones, and crown-of-thorns outbreaks) that can cause high mortality of corals, nor does it account for differences in recruitment rates, both of which have potentially large effects on local abundance. Linking environmental gradients to corresponding gradients in species abun- 
dance will require demographic approaches that explicitly integrate the energetic effects of environmental gradients with estimates of species- and size-specific mortality rates, and rates of recruitment.

Based on a mechanistic understanding of speciesspecific relationships between dominant environmental gradients and metabolic processes, our study quantifies the conditions that allow different coral species to survive and reproduce. Given the current threats to coral reefs worldwide, this framework may be particularly useful for predicting environmental tolerances of different species. Our results highlight the importance of incorporating organism size into physiological models and investigations of niche size: for corals, colony size directly influences the conditions under which a positive energy balance is possible. In addition, this study demonstrates the utility of process-based models for quantifying how physiology influences ecology, and for predicting the ecological consequences of varying environmental conditions.

\section{ACKNOWLEDGMENTS}

We thank K. Anthony for early discussions about this work and assistance with design of respirometry chambers. Thanks also to R. Gegg, G. Ewels, K. Arrowsmith, and G. Reeves for technical support, and to E. Graham, C. Glasson, M. Magnusson, and staff of One Tree Island Research Station for assistance with field work. This is a contribution from the Australian Research Council Centre of Excellence for Coral Reef Studies.

\section{Literature Cited}

Anthony, K. R. N., and S. R. Connolly. 2004. Environmental limits to growth: physiological niche boundaries of corals along turbidity-light gradients. Oecologia 141:373-384.

Anthony, K. R. N., and K. E. Fabricius. 2000. Shifting roles of heterotrophy and autotrophy in coral energetics under varying turbidity. Journal of Experimental Marine Biology and Ecology 252:221-253.

Anthony, K. R. N., and O. Hoegh-Guldberg. 2003a. Kinetics of photoacclimation in corals. Oecologia 134:23-31.

Anthony, K. R. N., and O. Hoegh-Guldberg. 2003b. Variation in coral photosynthesis, respiration and growth characteristics in contrasting light microhabitats: an analogue to plants in forest gaps and understoreys. Functional Ecology 17:246259.

Antoine, M. E., and B. McCune. 2004. Contrasting fundamental and realized ecological niches with epiphytic lichen transplants in an old-growth pseudotsuga forest. Bryologist 107:163-173.

Austin, M. P., A. O. Nicholls, and C. R. Margules. 1990. Measurement of the realized quantitative niche: environmental niches of five Eucalyptus species. Ecological Monographs 60:161-177.

Carpenter, R. C., and S. L. Williams. 1993. Effects of algal turf canopy height and microscale substratum topography on profiles of flow speed in a coral forereef environment. Limnology and Oceanography 38:687-694.

Carpenter, R. C., and S. L. Williams. 2007. Mass transfer limitation of photosynthesis of coral reef algal turfs. Marine Biology 151:435-450.

Chalker, B. E., W. C. Dunlap, and J. K. Oliver. 1983. Bathymetric adaptations of reef-building corals at Davies reef, GBR, Australia II. Light saturation curves for photosynthesis and respiration. Journal of Experimental Marine Biology and Ecology 73:37-56.
Chase, J. M., and M. A. Leibold. 2003. Ecological niches: linking classical and contemporary approaches. University of Chicago Press, London, UK.

Connell, J. H. 1961. The influence of interspecific competition and other factors on the distribution of the barnacle Chthamalus stellatus. Ecology 42:710-723.

Denny, M. W. 1988. Biology and the mechanics of the waveswept environment. Princeton University Press, Princeton, New Jersey, USA.

Edmunds, P. 2006. Temperature-mediated transitions between isometry and allometry in a colonial, modular invertebrate. Proceedings of the Royal Society B 273:2275-2281.

Elahi, R., and P. J. Edmunds. 2007. Determinate growth and the scaling of photosynthetic energy intake in the solitary coral Fungia concinna (Verrill). Journal of Experimental Marine Biology and Ecology 349:183-193.

Falkowski, P. G., and J. A. Raven. 1997. Aquatic photosynthesis. Blackwell Science, Malden, Massachusetts, USA.

Falter, J. L., M. J. Atkinson, R. J. Lowe, S. G. Monismith, and J. R. Koseff. 2007. Effects of non-local turbulence on the mass transfer of dissolved species to reef corals. Limnology and Oceanography 52:274-285.

Fulton, C., and D. R. Bellwood. 2005. Wave-induced water motion and the functional implications for coral reef fish assemblages. Limnology and Oceanography 50:255-264.

Gardella, D. J., and P. J. Edmunds. 1999. The oxygen microenvironment adjacent to the tissue of the scleractinian Dichocoenia stokesii and its effects on symbiont metabolism. Marine Biology 135:289-295.

Greulich, S., G. Bornette, C. Amoros, and J. G. M. Roelofs. 2000. Investigation on the fundamental niche of a rare species: an experiment on establishment of Luronium natans. Aquatic Botany 66:209-224.

Grottoli, A. G., L. J. Rodrigues, and J. E. Palardy. 2006. Heterotrophic plasticity and resilience in bleached corals. Nature 440:1186-1189.

Helmuth, B. S., K. P. Sebens, and T. L. Daniel. $1997 a$. Morphological variation in coral aggregations: branch spacing and mass flux to coral tissues. Journal of Experimental Marine Biology and Ecology 209:233-259.

Helmuth, B. S., E. F. Stockwell, and D. R. Brumbaugh. $1997 b$. Morphological and environmental determinants of mass flux to corals. Proceedings of the Eighth International Coral Reef Symposium 2:1103-1108.

Hoegh-Guldberg, O., et al. 2007. Coral reefs under rapid climate change and ocean acidification. Science 318:17371742 .

Hoogenboom, M. O., K. R. N. Anthony, and S. R. Connolly. 2006. Energetic cost of photoinhibition in corals. Marine Ecology Progress Series 313:1-12.

Houlbreque, F., E. Tambutte, and C. Ferrier-Pages. 2003. Effect of zooplankton availability on the rates of photosynthesis, and tissue and skeletal growth in the scleractinian coral Stylophora pistillata. Journal of Experimental Marine Biology and Ecology 296:145-166.

Hurd, C. L. 2000. Water motion, marine macroalgal physiology, and production. Journal of Phycology 36:453-472.

Hutchinson, G. E. 1957. Concluding remarks. Cold Spring Harbor Symposium on Quantitative Biology 22:415-427.

Jokiel, P. L., and J. I. Morrisey. 1986. Influence of size on primary production in the reef coral Pocillopora damicornis and the macroalga Acanthophora spicifera. Marine Biology 91:15-26.

Jones, M. M., P. Olivas Rojas, H. Tuomisto, and D. B. Clark. 2007. Environmental and neighbourhood effects on tree fern distributions in a neotropical lowland rain forest. Journal of Vegetation Science 18:13-24.

Kearney, M. 2006. Habitat, environment and niche: what are we modeling? Oikos 115:186-191. 
Kearney, M., and W. P. Porter. 2004. Mapping the fundamental niche: physiology, climate, and the distribution of a nocturnal lizard. Ecology 85:3119-3131.

Kim, K., and H. R. Lasker. 1998. Allometry of resource capture in colonial cnidarians and constraints on modular growth. Functional Ecology 12:646-654.

Koch, E. W. 1994. Hydrodynamics, diffusion-boundary layers and photosynthesis of the seagrasses Thallasia testudinum and Cymodocea nodosa. Marine Biology 118:767-776.

Kooijman, S. A. L. M. 2000. Dynamic energy and mass budgets in biological systems. Second edition. Cambridge University Press, Cambridge, UK.

Larkum, A. W. D., E.-M. W. Koch, and M. Kuhl. 2003. Diffusive boundary layers and photosynthesis of the epilithic algal community of coral reefs. Marine Biology 142:10731082.

Lesser, M. P., V. M. Weis, M. R. Patterson, and P. L. Jokiel. 1994. Effects of morphology and water motion on carbon delivery and productivity in the reef coral, Pocillopora damicornis (Linnaeus): diffusion barriers, inorganic carbon limitation and biochemical plasticity. Journal of Experimental Marine Biology and Ecology 178:153-179.

Marsh, J. A. 1970. Primary productivity of reef-building calcareous red algae. Ecology 51:255-263.

Miller, M. W. 1995. Growth of a temperate coral: effects of temperature, light, depth, and heterotrophy. Marine Ecology Progress Series 122:217-225.

Muscatine, L., L. R. McCloskey, and R. E. Marian. 1981. Estimating the daily contribution of carbon from zooxanthellae to coral animal respiration. Limnology and Oceanography 26:601-611.

Nobel, P. S. 1983. Biophysical plant physiology and ecology. W. H. Freeman, San Francisco, California, USA.

Patterson, M. R. 1992. A chemical engineering view of cnidarian symbioses. American Zoologist 32:566-582.

Patterson, M. R., and K. P. Sebens. 1989. Forced convection modulates gas exchange in cnidarians. Proceedings of the National Academy of Sciences (USA) 86:8833-8836.

Patterson, M. R., K. P. Sebens, and R. R. Olson. 1991. In situ measurements of flow effects on primary production and dark respiration in reef corals. Limnology and Oceanography 36:936-948.

Porter, J. W. 1976. Autotrophy, heterotrophy, and resource partitioning in Caribbean reef-building corals. American Naturalist 110:731-742.

Pulliam, H. R. 2000. On the relationship between niche and distribution. Ecology Letters 3:349-361.

Sanford, L. P., and S. M. Crawford. 2000. Mass transfer versus kinetic control of uptake across solid-water boundaries. Limnology and Oceanography 45:1180-1186.

Scharf, F. S., F. Juanes, and R. A. Rountree. 2000. Predator size-prey size relationships of marine fish predators: interspecific variation and effects of ontogeny and body size on trophic-niche breadth. Marine Ecology Progress Series 208: 229-248.

Sebens, K. P., and A. S. Johnson. 1991. Effects of water movement on prey capture and distribution of reef corals. Hydrobiologia 226:91-101.

Shashar, N., Y. Cohen, and Y. Loya. 1993. Extreme diel fluctuations of oxygen in diffusive boundary layers surrounding stony corals. Biological Bulletins 185:455-461.

Stimson, J. 1985. The effect of shading by the table coral Acropora hyacinthus on understory corals. Ecology 66:40-53.

Veron, J. E. N. 2000. Corals of the world. Australian Institute of Marine Science, Townsville, Australia.

Ward, S. 1995. The effect of damage on growth, reproduction and storage of lipids in the scleractinian coral Pocillopora damicornis (Linnaeus). Journal of Experimental Marine Biology and Ecology 187:193-206.

Webb, C. O., and D. R. Peart. 2000. Habitat associations of trees and seedlings in a Bornean rain forest. Journal of Ecology 88:464-478.

West, G. B., et al. 1997. A general model for the origin of allometric scaling laws in biology. Science 276:122-126.

Whittaker, R. H., S. A. Levin, and R. B. Root. 1973. Niche, habitat, and ecotope. American Naturalist 107:321-338.

Wright, J. W., K. F. Davies, J. A. Lau, A. C. McCall, and J. K. McKay. 2006. Experimental verification of ecological niche modeling in a heterogeneous environment. Ecology 87:24332439.

\section{APPENDIX A}

Flow speed calibration of respirometry chambers (Ecological Archives E090-053-A1).

\section{APPENDIX B}

Multivariate regression analysis of the combined effects of light and flow on protein content and reproductive output (Ecological Archives E090-053-A2).

\section{APPENDIX C}

Sensitivity of niche boundaries to light acclimation (Ecological Archives E090-053-A3). 